\title{
STERNOCLEIDOMASTOID (SCM) MUSCLE FLAP AFTER PAROTIDECTOMY
}

\author{
Ramraj R1, Vishnu M. $L^{2}$ \\ ${ }^{1}$ Senior Consultant Surgeon, Department of General Surgery, SUT Hospital, Pattom, Thiruvananthapuram. \\ ${ }^{2}$ Assistant in the Department, SUT Hospital, Pattom, Thiruvananthapuram.
}

\begin{abstract}
BACKGROUND

Parotidectomy ${ }^{1}$ is a routinely undertaken procedure by general surgeons and ENT surgeons; however, the risk of facial nerve injury and further deformity is a scare of the patient and nightmare of the operating surgeon, thus obtaining consent for the surgery is a difficult task of the surgeon. Most patients are happy after surgery; however, a depressed facial contour is a point of significant dissatisfaction for the patient. Another point of concern after superficial or total parotidectomy is Frey syndrome, ${ }^{2}$ which is seen in almost $80 \%,{ }^{2}$ but becomes noticed or symptomatic only in about $10 \%-12 \%{ }^{2}$ Many a number of attempts have been made with fascia lata, dermal fat, platysma, temporalis fascia, sternocleidomastoid muscle and submuscular aponeurotic sheath of the face to overcome these disabling issues. The sternocleidomastoid muscle flap with its superiorly based perfusion from occipital artery and superior thyroid artery is an effective tool in preventing Frey syndrome and avoiding a pitted deformity in the periauricular region, thus achieving facial symmetry. The advantage of this muscle over the other alternatives described is that it has lower chance of necrosis and it provides cover over a larger area and its design is easier.

The objective of the study was to assess the cosmetic and functional outcome of primary sternocleidomastoid muscle flap undertaken on post parotidectomy patients with reference to the cosmetic outcome, occurrence of Frey syndrome and sensation to the ear lobe.
\end{abstract}

\section{MATERIALS AND METHODS}

This descriptive study was undertaken on 22 patients, among whom 14 underwent superficial parotidectomy and 8 total conservative parotidectomy.

\section{RESULTS}

Among the 22 patients who underwent the procedure after parotidectomy, 4 were males and 18 were females. There were 14 superficial parotidectomy and 8 total conservative parotidectomy. The histopathology report was malignancy in 6 patients, pleomorphic adenoma in 14 patients and Warthin's tumour in 2. Satisfactory cosmetic outcome was possible in 21 patients. One patient had marginal necrosis of the flap and a pitted scar (post radiation patient) requiring PMMC (pectoralis major myocutaneous flap) cover. Frey syndrome occurred in one patient in spite of the flap. Ear lobule sensation was preserved in $20 / 22$ patients.

\section{CONCLUSION}

Partial thickness superiorly based on sternocleidomastoid flap 3,4 provides exemplary cosmetic outcome following either superficial or total conservative parotidectomy and it significantly lowers the incidence of Frey syndrome.

\section{KEYWORDS}

Sternocleidomastoid Muscle Flap, Parotidectomy, Frey Syndrome.

HOW TO CITE THIS ARTICLE: Ramraj R, Vishnu M. L. Sternocleidomastoid (SCM) muscle flap after parotidectomy. J. Evolution Med. Dent. Sci. 2018;7(06):714-718, DOI: 10.14260/jemds/2018/162

\section{BACKGROUND}

Parotidectomy either superficial or total conservative is the most effective treatment for benign and malignant neoplasms of the parotid gland. Most patients and some surgeons are aversed to this concept of treatment for fear of the complications following parotidectomy ranging from apraxia to the facial nerve, partial or total paralysis of the facial nerve, loss of sensation to the ear lobule, ${ }^{5}$ pitted pre-auricular deformity, Frey syndrome and many others. Among these complications, the most important concern of the surgeon will be to prevent facial nerve injury, Frey syndrome and

'Financial or Other Competing Interest': None.

Submission 12-01-2018, Peer Review 25-01-2018,

Acceptance 27-01-2018, Published 05-02-2018.

Corresponding Author:

Dr. Ramraj $R$

Senior Consultant Surgeon,

SUT Hospital, Pattom,

Thiruvananthapuram.

E-mail: ramrajr69@gmail.com

DOI: $10.14260 /$ jemds/2018/162

\section{(c) (1) $(9)$}

preservation of sensation to the ear lobule. A thorough knowledge of the neurovascular plane in parotid and its surrounding, an unhurried meticulous patient, bloodless dissection by the surgeon are the prerequisites for a favourable outcome.

A critical assessment of efficacy of sternocleidomastoid muscle flap which forms an effective tool in avoiding the major unfavourable outcome of surgery is undertaken in this descriptive study carried out on 22 patients.

Sternocleidomastoid muscle ${ }^{6}$ is rich in its vascularity from occipital artery from its upper third, superior thyroid artery in its mid portion and transverse cervical artery inferiorly. This muscle is therefore a commonly chosen one for orofacial reconstruction. Superiorly based partially split flap is used in post parotidectomy defect reconstruction. The most important structure to be attended during the dissection of the flap is the accessory nerve which passes through it. The SCM flap has an advantage over the other flaps as it fits into the defect perfectly, can be harvested without any deficits, has relatively no risk of skin necrosis 
and it provides a larger area under its cover, ${ }^{7}$ thus significantly decreasing the incidence of Frey syndrome.

\section{MATERIALS AND METHODS}

This descriptive study was conducted in 22 patients admitted in the Department of General Surgery for parotidectomy from April 2014 to October 2017. All surgeries were individually performed by a single surgeon (myself). A uniform technique of parotidectomy was performed.

All patients admitted for parotidectomy went through a proper evaluation of history and physical examination which were recorded. All patients underwent routine blood examination consisting of haemoglobin estimation, total count, differential leucocytes count, ESR, blood sugar, blood urea, serum creatinine, serum sodium and serum potassium. X-ray chest and ECG (all leads) were included in the list of investigations. Imageology namely ultrasonography, CT scan or MRI was considered depending on the type of case to identify the preoperative anatomy and to plan surgery.

\section{Operative Technique}

Surgery was undertaken under general anaesthesia. Patient lying in the supine position with head tilted to the opposite side and a sandbag beneath the shoulder for adequate neck extension. The skin incision ${ }^{8}$ started from the level of the zygomatic bone in its preauricular limb curving down to go behind the ear lobule and then curving down over the sternocleidomastoid muscle to reach the upper crease of neck. ${ }^{8}$

Superficial or total conservative parotidectomy was performed depending on the placement of the lesion and the anticipated pathology in the conventional way. The trunk of facial nerve was identified first followed by identification and securing of by its division, all branches and its intercommunicating rami. ${ }^{9}$ Other important structures in the fasciovenous plane namely retromandibular vein and terminal branches of external carotid artery were identified and secured. The use of haemostatic cautery was kept minimum and ligatures were used when required utilising 40 polyglactin. A superiorly based partial thickness SCM flap was harvested, carefully preserving vascularity received from occipital artery and the same was rotated anteriorly to cover the defect over the facial nerve and its branches, retromandibular vein, the branches of the external carotid artery and masseter muscle.

The flap was sutured to remnant parotid fascia and masseteric fascia avoiding a direct or indirect hitch or compression on the branches of the facial nerve. Specific care was executed during the dissection to avoid injury to the spinal accessory nerve, which pass through the SCM. ${ }^{10}$ After thorough haemostasis, a number 12 suction drain was placed, and the wound was sutured using 2-0 polyglactin for the subcutaneous tissue and monofilament 4-0 polyglecaprone subcuticular sutures for skin. Suction was removed on Day 1 or Day 2 depending upon individual cases. Patient was discharged on Day 3 to Day 4.

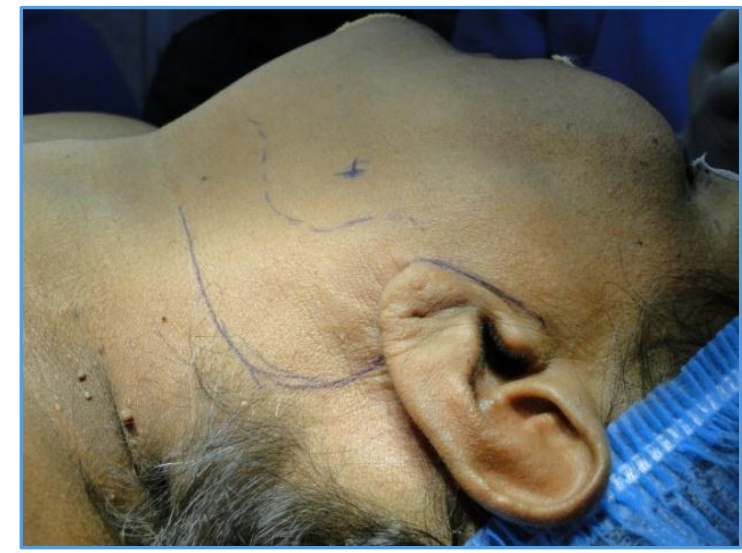

Figure 1. Incision

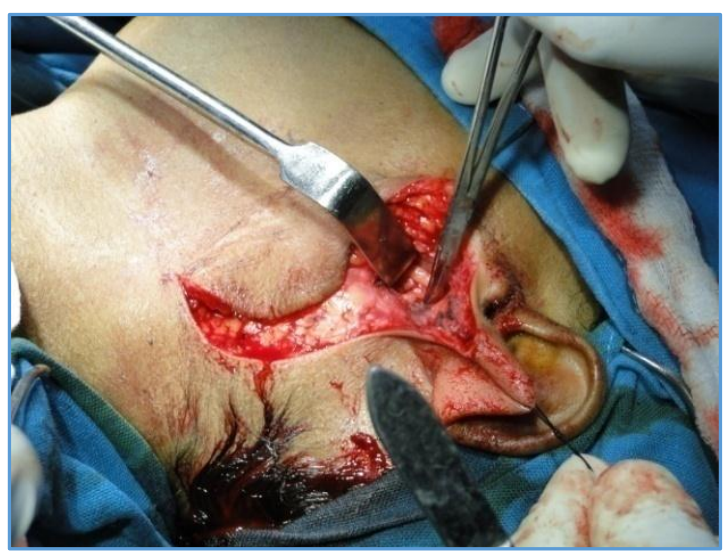

Figure 2. Initial Dissections

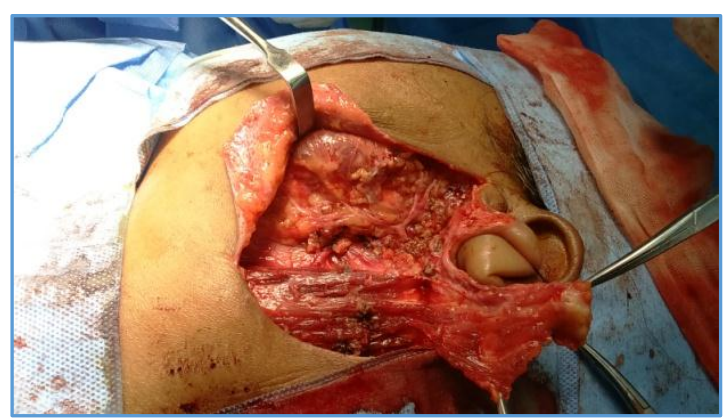

Figure 3. Completed Parotidectomy with Harvested Superiorly based SCM Flap

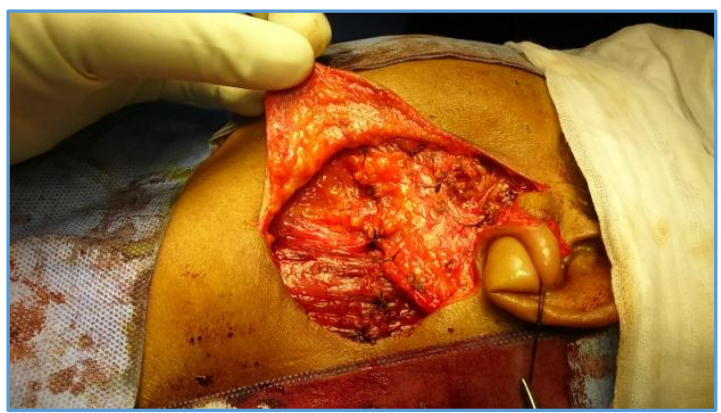

Figure 4. Flap Sutured Perfectly to cover the entire Neurovascular Structures taking care of Facial Nerve 


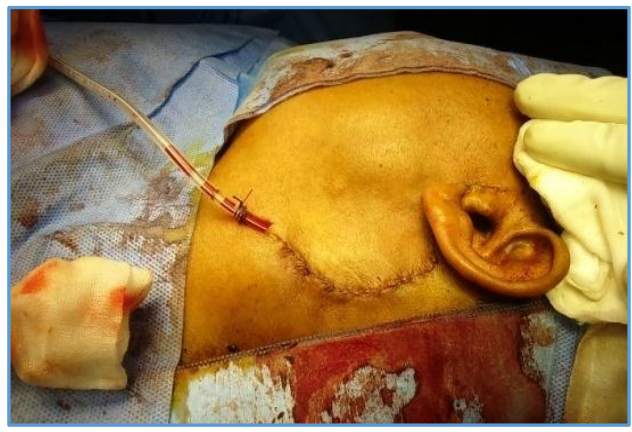

Figure 5. Subcuticular Closure with Drain

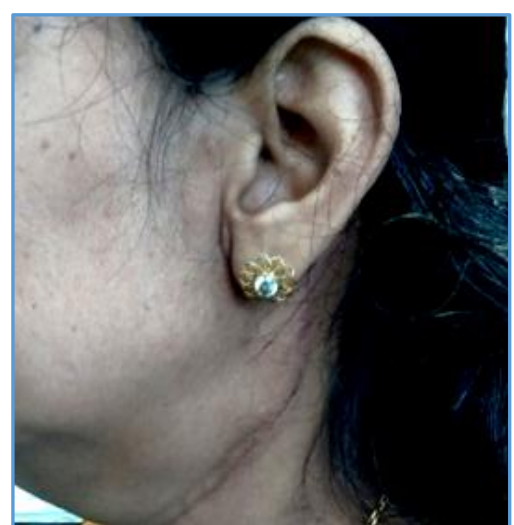

Figure 6. Final Result

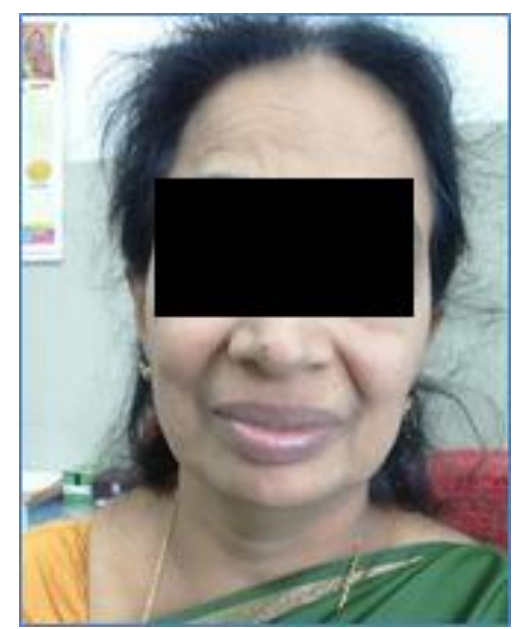

Figure 7. Result at $6^{\text {th }}$ Month of Surgery proving Perfect Bilateral Symmetry and Cosmesis

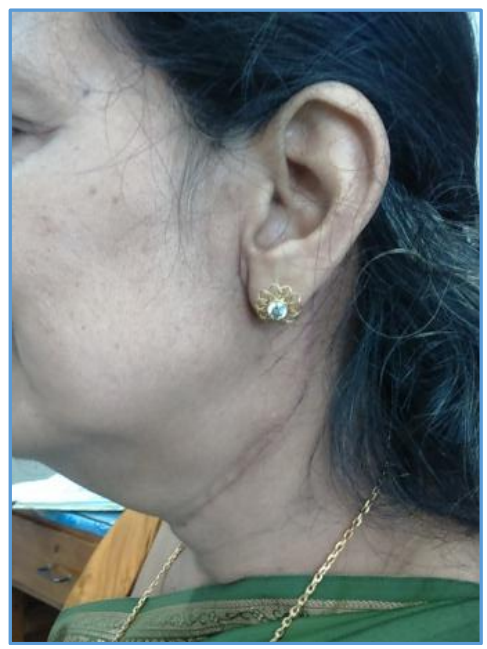

Figure 8. Operated Side

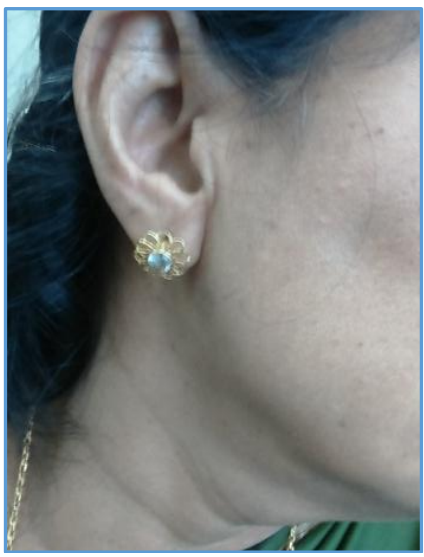

Figure 9. Normal Side

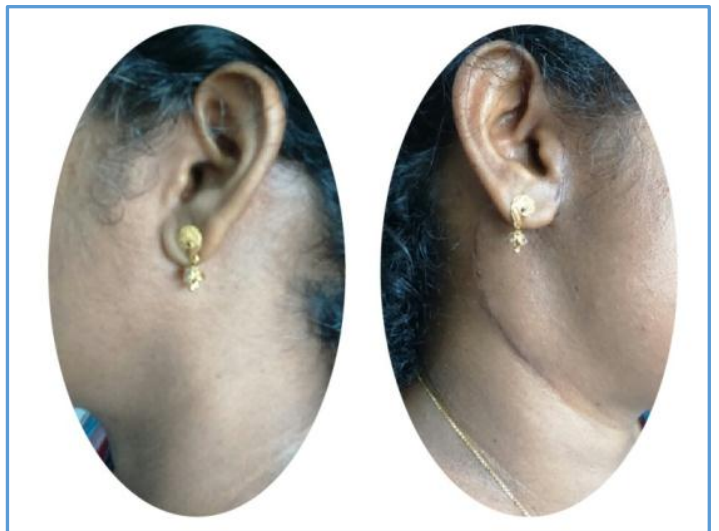

Figure 10. Normal Side

Figure 11. Operated Side

Another example of satisfactory outcome at 3 months using SCM flap.

\section{Ethics}

Evaluation and surgical procedure undertaken on all patients were in accordance with the ethical standards. Consent from the ethical and scientific committee of the hospital was sought prior to the commencement of the study.

\section{Statistics}

\begin{tabular}{|c|c|c|}
\hline \multicolumn{3}{|c|}{ Patient Profile } \\
\hline Gender & No. of Patients & Percentage \\
\hline Male & 4 & $18.18 \%$ \\
\hline Female & 18 & $81.81 \%$ \\
\hline Total & 22 & \\
\hline \multicolumn{3}{|c|}{ Table 1. Patient Profile } \\
\hline
\end{tabular}

\begin{tabular}{|c|c|c|}
\hline Type of Surgery & $\begin{array}{c}\text { Number of } \\
\text { Patients }\end{array}$ & Percentage \\
\hline Superficial parotidectomy & 14 & $63.63 \%$ \\
\hline $\begin{array}{c}\text { Total conservative } \\
\text { parotidectomy }\end{array}$ & 8 & $36.36 \%$ \\
\hline Total & 22 & \\
\hline
\end{tabular}

\begin{tabular}{|c|c|c|}
\hline Histopathology & No. of Patients & Percentage \\
\hline Pleomorphic adenoma & 14 & $63.63 \%$ \\
\hline Warthin's tumour & 2 & $09.09 \%$ \\
\hline Malignancy & 6 & $27.27 \%$ \\
\hline Total & 22 & \\
\hline \multicolumn{2}{|c|}{ Table 3. Histopathology } \\
\hline
\end{tabular}




\begin{tabular}{|c|l|}
\hline Degree & \multicolumn{1}{c|}{ Appearance } \\
\hline 0 & $\begin{array}{l}\text { Normal appearance, symmetrical to the opposite } \\
\text { side }\end{array}$ \\
\hline 1 & $\begin{array}{l}\text { Minimal asymmetry, barely noticeable from a } \\
\text { short distance }\end{array}$ \\
\hline 2 & $\begin{array}{l}\text { Mild asymmetry, noticeable but with no } \\
\text { disfigurement }\end{array}$ \\
\hline 3 & $\begin{array}{l}\text { Moderate asymmetry, mainly in the preauricular } \\
\text { area, apparent when looking at the patient }\end{array}$ \\
\hline 4 & $\begin{array}{l}\text { Severe asymmetry with deep preauricular and } \\
\text { retromandibular groove }\end{array}$ \\
\hline 5 & $\begin{array}{l}\text { Severe asymmetry with deep preauricular and } \\
\text { retromandibular groove with obvious scar }\end{array}$ \\
\hline \multicolumn{2}{|c}{ Table 4. Visual Analogue Score } \\
\hline
\end{tabular}

\begin{tabular}{|c|c|c|}
\hline \multicolumn{2}{|c|}{ Outcome } & $\begin{array}{c}\text { Outcome in } \\
\text { Percentage }\end{array}$ \\
\hline Facial nerve neurapraxia & 3 & $13.63 \%$ \\
\hline Permanent palsy of a branch & 1 & $4.54 \%$ \\
\hline Frey's syndrome & 1 & $4.54 \%$ \\
\hline Ear lobule sensation loss & None & \\
\hline \multicolumn{2}{|c|}{ Table 5. Outcome } \\
\hline
\end{tabular}

\begin{tabular}{|c|c|}
\hline \multicolumn{2}{|c|}{ Cosmetic Outcome } \\
\hline Visual analogue score by blinded peer & $0-1$ \\
\hline Visual analogue score by patient & 1 \\
\hline \multicolumn{2}{|c|}{ Table 6. Cosmetic Outcome } \\
\hline
\end{tabular}

\section{RESULTS}

The study was performed on 22 patients, among whom 4 were males and 18 were females. The age of the patient ranged from 16 years to 72 years. Of the 22 patients, 14 underwent superficial parotidectomy and 8 total conservative parotidectomy. The final histopathology diagnosis in 14 were pleomorphic adenoma, 2 were Warthin's tumour and 6 were malignant. Facial nerve function, greater auricular nerve function were assessed on POD 1 and were followed up at 3 months, 6 months and 1 year. Frey syndrome was evaluated objectively at 6 months and subsequently every 6 months. The outcome of SCM flap was assessed using a designed visual analogue score (Table 1). Neuroapraxia11 was observed in $3 / 22$ patients, which recovered fully in 6 weeks. In one patient the zygomatic branch had to be severed for oncological ${ }^{12}$ reasons, as the nerve was going into mucoepidermoid cancer and thus one patient had permanent palsy of one branch. Frey syndrome (gustatory sweating over an area on the anterior most part close to masseter- $3 \mathrm{~cm}^{2}$ ) was seen in one patient in spite of perfectly placed SCM flap.

\section{DISCUSSION}

Routinely parotid tumours undergo surgical removal resulting in a pitted scar in front of the ear on the side of surgery. Many ideas have been postulated by innumerable surgeons from time-to-time to overcome the cosmetic deformity and the functional deficits after parotidectomy. The first to describe a face lift incision with SCM flap for parotidectomy was Appiani and Delfino. ${ }^{12}$ Terris et al used only face lift incision as an innovation avoiding a scar in the neck. Endoscopy assisted parotidectomy was first undertaken by Lin et al.12 SMAS advancement through face lift incision was proposed by Foustanos and Zavrides. ${ }^{12}$
In our series, a superiorly placed SCM flap was used. Careful placement of sutures attaching the flap to the remnant parotid fascia was the most important step. In malignant tumours of the parotid in our series, the SCM flap was used only with a caution that a tumour recurrence would possibly be hidden under the transposed flap. ${ }^{13}$ The same was explained to the patient and relatives when total conservative parotidectomy was considered for suspected malignant lesion of parotid. ${ }^{14}$ The Frey syndrome that was noticed in one patient improved 15 with time and patient is tolerating the same. The cosmetic results in our study was exemplary and the score given by the patient was of degree one and a blinded second person made a score of zero and one.

\section{CONCLUSION}

The superiorly based SCM flap offers exemplary cosmetic and functional benefit in avoiding an ugly scar and it significantly lowers the occurrence of Frey syndrome. There is no significant hazard to the patient's wellbeing when this procedure was undertaken. There is no reported damage to the spinal accessory nerve when the procedure was undertaken with the desired level of expertise.

\section{REFERENCES}

[1] Yu L T, Hamilton R. Frey's syndrome: prevention with conservative parotidectomy and superficial musculoaponeurotic system preservation. Ann Plast Surg 1992;29(3):217-22.

[2] Morfit HM, Kramish D. Auriculotemporal syndrome (Frey's syndrome) following surgery of parotid tumors. Am J Surg 1961;102(6):777-80.

[3] Laage-Hellman JE. Gustatory sweating and flushing after conservative parotidectomy. Acta Otolaryngol 1957;48(3):234-252.

[4] Blumenfeld RJ, Friedman JE. Intratympanic surgical treatment of Frey's syndrome. Arch Otolaryngol 1967;86(1):2-7.

[5] Wallis KA, Gibson T. Gustatory sweating following parotidectomy: correction by a fascia lata graft. $\mathrm{Br} \mathrm{J}$ Plast Surg 1978;31(1):68-71.

[6] Smith RO, Hemenway WG, Stevens KM, et al Jacobson's neurectomy for Frey's syndrome. Am J Surg 1970;120(4):478-81.

[7] Conley JJ, Clairmont AA. Dermal-fat-fascia grafts. Otolaryngology 1978;86(4 Pt 1):ORL-641-ORL-9.

[8] Kim SY, Mathog RH. Platysma muscle-cervical fasciasternocleidomastoid muscle (PCS) flap for parotidectomy. Head Neck 1999;21(5):428-33.

[9] Rubinstein RY, Rosen A, Leeman D. Frey syndrome: treatment with temporoparietal fascia flap interposition. Arch Otolaryngol Head Neck Surg 1999;125(7):808-11.

[10] Bugis SP, Young JE, Archibald SD. Sternocleidomastoid flap following parotidectomy. Head Neck 1990;12(5):430-5.

[11] Sanabria A, Kowalski LP, Bradley PJ. et al. Sternocleidomastoid muscle flap in preventing Frey's syndrome after parotidectomy: a systematic review. Head Neck 2012;34(4):589-98. 
[12] Foustanos A, Zavrides H. Face-lift approach combined with a superficial musculoaponeurotic system advancement flap in parotidectomy. $\mathrm{Br} \mathrm{J}$ Oral Maxillofac Surg 2007;45(8):652-5.

[13] Stranding S. Gray's Anatomy. The anatomical Basis of clinical practice. $41^{\text {st }}$ edn. Elsevier 2015.
[14] Nosan DK, Ochi JW, Davidson TM. Preservation of facial contour during parotidectomy. Otolaryngol Head Neck Surg 1991;104(3):293-8.

[15] Casler JD, Conley J. Sternocleidomastoid muscle transfer and superficial musculoaponeurotic system placation in the prevention of Frey's syndrome. Laryngoscope 1991;101(1 Pt 1):95-100. 